\title{
Comentarios al trabajo presentado por el doctor Eudoro Castillo V.
}

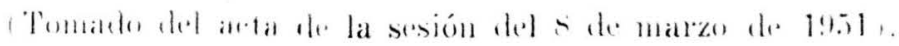

"En consideration al rabajo del foctor Castillo, la Presideneia concede It palabra al Profesor José del C. Acosil. quien felicita al ponent. $y$, aunque un lo ha practicaclo, considira al métoin de Aburel interesante, inofensivo $y$ ail. Entre contemporizatoin o intervnción, en caso de Mola, su lecelara por a b́ltima, previo un diagnóstico cierto, ya que hay el peligro de invasión; numad ha provocado el aborto, generalmente bace evacuación. Como la freruencia varía, propone una confrontación en todo (1) Instituto, pues pudiera sureder que lo rases se hubiesen acmmulado en $u$ solo servicio: en el suyo. por ejemplo, an el año de 1950, hubo tall solo un ea-6. En rllanto a accidenfes decenerativos no ha visto simo nin aso de corionpitelioma seeundario Mola. en 1947. en una mujer cilyo embarazo die cineo meses semejaba frune\% geme. lar a término; R. de Friedmamn negativa. Operada salió bien. pero 50 días uás tarde, se presentó con un cuadro de corioepitelioma confirmalo, después 3r histerectomía total, por la histología. considera que si la Mole furra extirpa. da precozmente se hubiese podido extirpar el corioepitelioma. Conoció otro easo secundario a un parto espontáneo, en que sr presentó metrorragia 30 días después del parto: la biopsia reveló un (oriocpitelioma.

Ductor Ramírez M.-Elad de la priwera pariente?

Doctor Acosta-27 años.

Doctor Ramirez-Pregunta la edad porque ha leido en algún autor que el liagnóstico de Mola en paciente mayor de 40 años, implica histerectomía abdominal total.

Doctor Acosta-Dicha conducta se justifica en europeos $\mathrm{y}$ americanos por la fuecuencia de la degeneración, pero entre nosotros, no sucede lo mismo y en su experiencia tiene varios casos de embarazos normales después de Mola.

Ramirez-Algunos autores dan un $8 \%$ como frecuencia de la degeneración $y$ por tal motivo, aconsejan la histerectomía total, especialmente en pacientes mayores. Además, no se debe intervenir con cureta, sino digitalmente o con cureta de falsos gérmenes, 15 días después de la expulsión.

Doctor Acosta-Acostumbra dilatación con bujias hasta el número $30 \mathrm{y}$ luégo cureta roma y expresión; en seguida limpia con gasa seea y practica enyodado de la ravidad; no tapona, sal- 
so (1)110 -

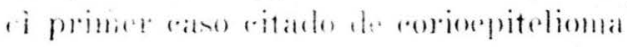

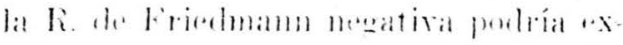

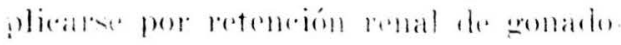

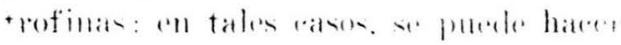

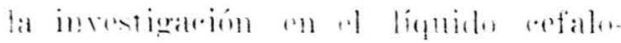
raliublus.

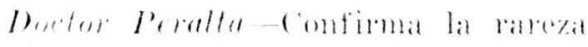

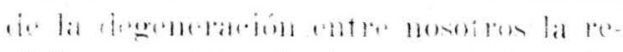
vision yor hize de lat estadistieas ded lastitute Nateional de Radimm, disele sli fmolaroin hasta 1946, y en las cuales no encontró ni un solo caso de corjoepi1. a! trabajo del doctor Castillo, le llama la atención no sólo la precisión en el diagnóstico, sino la siempre feliz reacción dinámico-nterina con el empleo del método de Aburel, ya que anteriormente se obturieron fracasos y anu peligro para el feto. por lo rual se llegó a prohibirlo en el serricio.

Doctor Lópe a E.-Se refiere a la disparidad de opiniones sobre la frecuenria d. la degenerarión. ya que hay muchos antores que califican a la Mola $\mathrm{Hi}$ datiforme penetrante como corioepitelioma. Pregunta a Castillo si las pacientes han sido seguidas.

Castillo-El control en la clientelic hospitalaria es prácticamente imposible.

Doctor Amaya-Relata un (asso oi)servado en el servicio de Ginerología en 1943: paciente de 22 años, quien consultó por una hemorragia post-partum; hecha la exploración se extrajo una ma:sa considerada como pólipo, que resultó ser un corioepitelioma. En otra paciente de 18 años, se extrajo una Mola que e] histólogo comsideró sospechosa de degeneración : sin embargo, a los ocho meses, hizo un embarazo normal. Se refiere para terminar a las difieultades diag-

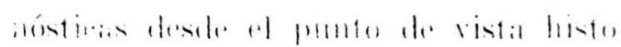
binicu.

l)

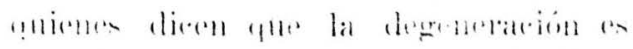

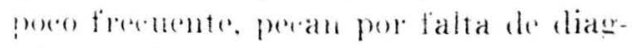

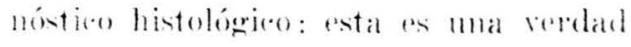
mmy grambe metre mentrus.

Drater Ramere .H. Eu el Institute

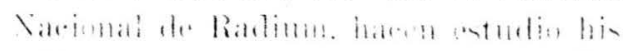

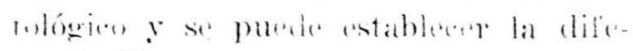
renriąión.

Profesor Acosta-Revisó las esta dísticas del Instituto Nacional de Radium y en total, sobre muchísimas historias. tan sólo había 6 o 7 casos de coroepitolioma hasta 1947.

Doctor Trdaneta-Entre las enfermas bservadas por él, en el Instituto Nacional de Radium, la indicación biopsia-endometrio no ha proporcionado ningún diagnóstico de corioepitelioma en tres años.

Profesor Aparicio-Está de acuerdo ‘n Afanador, en que la poca frecuencia de la degeneración entre nosotros puede deberse a la falta de estudio histológico: a medida que progresan los medios de investigación, se descubren nuevas entidades que antes se negaban. En el iratamiento se debe proceder con mucha prudencia.

Doctor Amaya-l'ropone remir las estadietioas pareiales de los servicios de obstetriciat y ginecología. y particulares. para presentar un trabajo colectivo, que ya seria más serio, sobre Mola Hidatifrome $y$ rorioepitelioma.

El senor Presidente-Aprueba la peticion de Amaya y cree que diehas estadísticas se pueden confrontar en la próxima sesión.

Héctor Enrique Pernal Secretario de Actas. 